\title{
ROTTWEILERS SAVAGE DEMOCRACY
}

\section{Barry Richards}

Jonathan Sacks ${ }^{1}$ spoke for a growing constituency when he called for our mass media (and he was speaking particularly of television) to be 'unafraid to claim the high ground of civic discourse and great ideals'. The citizens of a country at war, whatever their views on the war, will feel more acutely than at other times the need for a media discourse which can occupy that ground, not sparing us the reality of what is happening but staging our responses to it with as much respect and understanding as is possible. During the anguished and recriminatory phase which our national conversation is entering, our attention will be primarily elsewhere, on the war itself, but along the way we will be noting - perhaps more sharply than usual - the roles our media play in that conversation.

Post-war, we might then turn anew to their shortcomings Which programmes least embody the concept of civilisation as civil conversation, based on courtesy and a wish to discover things about other people and the world? Is it possible that a broadcast genre often celebrated for its integrity may be more damaging to our political culture than a lot of 'tabloid' style programming?

We all know about the rottweilers, the aggressively challenging interviewers who bite lumps out of politicians. They are often applauded as they do so, and feted as a major democratic advance on their forbears, the deferential interviewers who let politicians get away with murder.

\footnotetext{
1 'Television, narrative and conversation', in Culture and Communications ed. S. Higdon, ITC 2001.
} 
However it must be considered that these dogs are a threat to the public, in the sense that their clamorous barking is like a form of noise pollution which impairs the quality of democratic life in our public space. Or to take a more extreme analogy: their mauling of politicians provides a spectacle like those of criminal entertainments where vicious dogs are let loose on some other despised creature, and the worst is brought out in the audience.

Of course the sceptical persistence of an interviewer may sometimes perform an importantly useful role in opening an aspect of political reality to public gaze. But amongst the rottweilers, scepticism is enveloped in cynicism and hostility, in an attitude which on a daily and basic level is likely to have a number of adverse effects on audiences.

It is likely to promote cynicism about politics, it gratuitously polarises arguments and people, and it militates against creative thinking about problems in society and how to tackle them. Overall it brings a negativity and fractiousness to the emotional tone of our politics. This is in an age when the decline of traditional party affiliations and the rise of personal and emotional agendas in many areas of life means that the emotional dimensions of politics are of increasing importance

These are obviously serious charges against an influential form of media content. Not only are the rottweilers accepted, they are probably widely popular. And in many cases it is easy to see why this is so. They can transmute instantly into loveable labradors. When not baring their teeth, they may come over as humorous, warm and 
decent people. Their approach to many topics is sensitive, and their treatment of nonpolitician interviewees is usually very respectful. Arguably this makes their contribution to political culture all the more damaging, as they are easily identified with and have high credibility. They are probably seen as nearer to the TV news reader, who is trusted by $66 \%$ of the population to tell the truth, than they are to the journalist, trusted by 18\% (MORI, February 2003).

However a number of voices are now being raised questioning the trends towards attack and disrespect in news and current affairs presenting and in British political journalism as a whole. Some like John Lloyd ${ }^{2}$ are from within journalism. Some politicians too are fighting back (for example Clarkes Charles and Kenneth, and Clare Short), and other critical voices are from academia. Leading media academic Steven Barnett $^{3}$ has identified four phases of political journalism in the UK. From the postwar 'age of deference', in which journalists were 'fawning and submissive' to politicians, we have passed through the 'age of equal engagement', when both interviewers and their subjects were prepared to engage in civil debate, and then the ‘age of journalistic disdain’, in which journalists adopted attitudes of 'detached scepticism'. He likens his historical model to accounts of the evolution of American journalism in the same period. Now, he argues, we are in an 'age of contempt', in which journalists have moved from informed questioning to a 'relentlessly negative approach' and to 'unthinking ridicule' of politicians.

As well as this kind of historical framing, another kind of input which academics can make to this debate is in the careful scrutiny of what is actually said in interviews, and

\footnotetext{
2 ‘Media manifesto’, Prospect 79, October 2002, pp. 48-53.
} 
in the analysis of how this might be received by audiences. We could imagine a typology of common forms of attack by interviewers. Giving new life to an old cliché, these could be called 'soundbites'. Amongst the main categories of bite would be accusing, bossing, and wedge-driving. Accusations come in a number of sub-types. Interviewees are accused, usually in slightly less direct language than this, of being incompetents, weaklings, turncoats or liars. Bossing comes in various forms, all intended to construct the interviewee as the moral inferior of the interviewer. We can include here finger-wagging (usually conveyed in tone of voice), chopping off, and the Parthian shot. Lastly, wedge-driving involves a form of questioning that is designed to demonstrate that whatever policy or practice with which the interviewee is trying to resolve a conflict will inevitably fail. The interviewer is in effect pressing the case that 'the shit will hit the fan', and that whatever antagonisms are involved in the issue to hand are irreconcilable ones.

Why are the accusatory, contemptuous and cynical words of interviewers a problem? What is their impact on audiences? Evidence from audience research which has probably not been undertaken might be necessary to answer that question fully and with complete confidence, but we can reasonably propose that there are two serious risks here to the health of our political culture.

1. One is linked primarily to the accusing tendency, though it is also reinforced by contemptuous bossing. It is that respect for politicians, confidence in the democratic political process and belief in the sphere of politics as a worthy field of human endeavour are further eroded. Of course trust in politicians and in politics may have

\footnotetext{
3 'Will a crisis journalism in journalism provoke a crisis in democracy?' Political Quarterly 73(4), 2002, pp. 400-408.
} 
been in crisis anyway for other reasons, to do with the limits and flaws of political institutions, and the shortcomings of individual politicians. But instead of encouraging us to see these problems as potentially remediable, rottweiler interviewing leads us to despair and to call a plague on all their houses.

This is not only because politics is presented as adversarial ritual. Nor is it only because one politician after another, across the political spectrum, is treated as a potential or actual liar, chameleon, weakling or incompetent. It is also because the interviewees, with whom as audience we spontaneously identify, take up one contradictory position after another. In order to retain a confrontationist stance with different interviewees, the interviewer must first adopt one position, then - with equal relish - its opposite. As John Humphries has pointed out ${ }^{4}$, he cannot believe in all positions. So we are schooled by the presenters as our role models in the assumption that positions are things to be adopted for argument's sake only. There is a current of urbane nihilism in this, and it carries us far beyond a subtle use of devil's advocacy to clarify a debate, into a world where we have argument for argument's sake (at which point most people close down on politics, as they do on Parliamentary yah-boo) and where nobody can be believed. Comprehensive cynicism, or an impractical idealistic rejection of the world as it is, are the only positions then available.

2. Secondly, there is an effect likely to flow from the wedge-driving practice, which seeks to demonstrate that problems are unresolvable and conflicts are absolute. If it has any effect on how the audience understand politics, this must encourage views of the world as hopelessly ridden with unmanageable antagonisms. Such views either

\footnotetext{
${ }^{4}$ See Paul Donovan, All Our Todays, Jonathan Cape 1997, p. 135
} 
lead in turn to more cynical despair, or feed fundamentalisms of all kinds. This compulsion of journalists and especially interviewers to try and drive wedges into negotiations as they are taking place is something we have heard and seen much of in the Iraq debate, and is one area where we may wonder at times about how aware some journalists are of their responsibilities in the political process.

The wedge-driving proclivity of interviewers invokes impoverished ways of thinking amongst audiences, for whom new resolutions and creative compromises are less likely to be entertained as they fall outside the poles of antagonism to which the interview constantly returns.

Overall this has a corrosive effect on thinking. Now it is a piece of conventional wisdom in media research that the media cannot tell us what to think, but they can tell us what to think about. In fact this power of agenda-setting can amount to a power to tell us how to think. At least it aspires to that: the recurrent message of much political journalism, and especially of the radio and television interview, is that we must think in cynical and pessimistic ways. We must assume that politicians are adopting incoherent or unworkable positions, and that they are striving to hide inconsistencies, cover up failures and deny conflicts with colleagues or allies.

There are two issues here that should be noted. One is the complicity of politicians in their own humiliation. Despite robust examples over the years of refusals to be 'kebabbed', many allow themselves to be bullied and pilloried with regularity. There seems to be a variety of motives for this. Some politicians have said how much they enjoy the antagonistic encounters with interviewers, seeing them as another part of the 
pleasurable scrapping of politics, perhaps implying that there is a harmless theatricality to these contests. Others seem to grit their teeth and accept it unquestioningly as a price of the job, a regrettable necessity in which the main thing is not to get upset. And of course there is the view that politicians have made a major contribution to the evolution of the interview by their increasing use of it as an opportunity to make particular statements regardless of the questions, and by their schooled evasiveness, tactics which provoke the interviewer into more aggressive questioning just as the news management techniques of government have hastened the descent of the press into junkyard journalism. To say this doesn't condone the rottweiler style, but does help to explain its rise, even if the growth of news management was itself a response to an already disrespectful and wayward fourth estate.

The second is the relationship of aggressive interviewing to the question of interviewer bias. One research study has found ${ }^{5}$ that more dominant and aggressive interviewers show more preferential behaviour. Where interviewers are selfindulgently expressive, as is increasingly the case, the possibilities for differential treatment of interviewees via non-verbal channels are greater. Even though interviewers appear uniformly hostile to all, subtle differential effects may build over time in relation to individual politicians, if not parties, or occasionally swamp an individual interview. So although systematic bias is not now such a major issue in media treatments of politics, the fierceness of the rottweilers may vary in more idiosyncratic ways.

\footnotetext{
${ }^{5}$ Elisha Babad, 'Preferential treatment in interviewing: evidence from nonverbal behaviour', Political Communication 16(3), 1999, pp. 337-358.
} 
Overall, we need to ask where this rottweiler distemper comes from, and what sustains it. Let's consider two socio-cultural sources of the phenomenon, one on the supply side and one on the demand side.

On the supply side, many of today’s leading presenters, while very varied as characters, are people whose intellectual formation was inevitably much influenced by the radicalisation of the intelligentsia which occurred in Britain in the seventies. While the theories of revolution which led this radicalisation are no longer widely held, they have left a broad legacy in an underlying worldview which is still prevalent amongst liberal/left people, especially in academia and the media. In this worldview, as John Lloyd has pointed out, truth is assumed to be always hidden, requiring aggressive digging to reveal it. It is also imagined to reside ultimately and only in conflict; politics is seen as basically about the fomenting and exploitation of conflict, and the role of national political leaders is often to conceal conflict or pronounce false solutions to it. And this worldview also starts from the assumption that most authorities, and especially political leaders, are corrupt or degenerate.

This mindset is perhaps better seen as an emotional toning of outlooks rather than as a substantive cognitive worldview. It now predominates in the treatment of politics across all media outlets, and feeds the rottweilers in their urges to tear up the delicate compromises and uneasy alliances which politics partly consists of. And too much political journalism appears to be guided more by this suspicious and acerbic mood of the elite rather than by considerations of what would best contribute to a forwardlooking and inclusive democratic culture. 
On the demand side, we need to ask why audiences are prepared to watch the rituals of aggressive cross-examination to the extent that they are. Barnett in fact partly blames audiences, in his argument that a major driver of the 'age of contempt' is the deregulation of the media, which has led to increased competitive pressures on journalists and editors to appeal to audiences with displays of nastiness and other forms of circulation- and ratings-boosting sensationalism. We should be wary of analyses that rest too heavily on the basically elitist assumption that mass audiences always want the cheap and the nasty, but there is clearly some appetite for blood amongst the audiences of programmes such as Newsnight and C4 News.

There are several complementary ways to understand the origins of this. One is that we are all influenced by the general culture of contempt which as argued above has been a negative fall-out of the radicalisation of the intelligentsia. We may not all spontaneously embrace it with as much enthusiasm as our metropolitan opinionleaders in the media elites, but we have enough of it to be willing spectators of various blood-sports. The current popularity of various forms of 'nasty TV' in quiz shows and reality TV is evidence for this.

Another is to do with the way in which the serious media treatment of politics is traditionally a rather dry business, lacking the everyday repertoire of human feeling. While stylised forms of ideological passion (for things like the NHS, the pound and education) are routinely expressed by politicians, the messier side of emotional life is not part of the media discourse of politics. Little air-time is given to exploring how complex the emotional bases of these positive commitments may be, nor to how both 
politicians and citizens are influenced in their political decisions by negative feelings such as guilt and envy, and by mixed feelings of doubt and ambivalence.

Of course it is a key responsibility of the media to help create a space for politics in which personal and emotional factors can be subjected to a calm and rational scrutiny. But what we can call the emotional deficit in political discourse, the absence of a spontaneous and full range of emotional expression, leaves audiences hungry for anything which engages the passions and brings some psychological life and colour to the intellectually demanding work of figuring out what is best for us as a society. If all that is on offer is a kind of courtroom drama led by interviewers fired with righteous passion, then people will go for that. But excessive consumption of this kind of material brings on a fever of negativity in a disillusioned audience, not clear thinking by an engaged citizenry. It may succeed at times in exposing the worst of politicians, but it risks bringing out the worst in all of us.

What's the alternative? In Barnett's historical account, there was a brief period in between deference and cynicism, when journalists approached politicians as equals, in a spirit of constructive engagement, and interviewing styles were grounded in courtesy and intellectual curiosity rather than scalp-hunting. Perhaps we can hope, in the turbulent post-war self examination which we face, for a restitution of this approach, as part of a larger ambition for our media to make more positive, respectful and emotionally complex contributions to our political culture. 